\title{
EFFECT OF PROPOFOL AND CPAP ON AIRWAY SIZE AND CONFIGURATION IN INFANTS
}

Denise Rohan MB, Christopher K. Macgowan PhD, Bruce A. Macpherson MD, Shi-Joon Yoo MD, Mark W. Crawford MBBS

Departments of Anesthesia and Diagnostic Imaging, The Hospital for Sick Children, University of

Toronto, Toronto, Ontario, M5G 1X8

INTRODUCTION General anesthetics attenuate upper airway muscle activity, rendering the airway vulnerable to obstruction. ${ }^{1}$ Infants are more susceptible to anesthesia-induced airway obstruction than older children and adults. ${ }^{2}$ Continuous positive airway pressure (CPAP) can prevent or treat airway obstruction during anesthesia. ${ }^{3}$ Using spin echo magnetic resonance imaging (MRI) to obtain high-resolution images of airway structures, we studied the interaction of propofol and CPAP on upper airway size and configuration in spontaneously breathing infants.

METHODS Research Ethics approval was obtained to study 8 infants aged 4 to 12 months undergoing MRI of the brain. Anesthesia was induced with propofol and glycopyrrolate, and maintained with a continuous infusion of propofol. Head position was standardized in the neutral position. MRI images were acquired using a GE 1.5 Tesla scanner and a quadrature head coil. A T1 weighted three-plane gradient echo localizer image was performed to identify the midline and allow selection of subsequent axial images. A T1-weighted single shot fast spin echo pulse sequence was used to acquire axial/oblique airway images at the level of the soft palate, base of tongue, and tip of epiglottis. Four sets of images were acquired in sequence: (1) during light propofol anesthesia at an infusion rate of $80 \mu \mathrm{g} / \mathrm{kg} / \mathrm{min}$ (PL), (2) after increasing the depth of propofol anesthesia by administering a bolus dose $(2.0 \mathrm{mg} / \mathrm{kg}$ ) and increasing the infusion rate to $240 \mu \mathrm{g} / \mathrm{kg} / \mathrm{min}$ (PD1), (3) during continued infusion of propofol $240 \mu \mathrm{g} / \mathrm{kg} / \mathrm{min}$ and application of CPAP $10 \mathrm{cmH}_{2} \mathrm{O}$ (PD + CPAP), (4) after removal of CPAP and continued infusion of propofol $240 \mu \mathrm{g} / \mathrm{kg} / \mathrm{min}$ (PD2). Images were analyzed by a blinded investigator.

RESULTS Increasing depth of propofol anesthesia decreased airway cross sectional area (CSA) at each anatomic level, resulting predominantly from a decrease in anteroposterior dimension.

Application of CPAP completely reversed the propofol-induced decrease in airway CSA, primarily by significantly increasing airway transverse dimension. Changes occurring at the level of the soft palate were typical and are shown in the Figure:
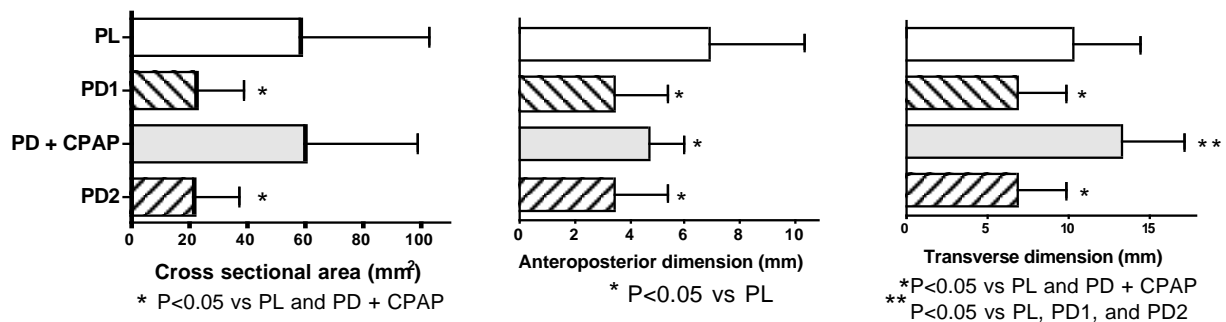

DISCUSSION CPAP reverses propofol-induced airway narrowing. Although airway CSA during deep anesthesia and application of CPAP was similar to that during light anesthesia, there were significant configurational differences.

REFERENCES (1). Br J Anaesth. 63:12-21 (2) J Appl Physiol 77: 918-24 (3) Anesth 84: 273-9 